\title{
The Outcomes of Radiosurgery for Arteriovenous Malformations-Experience of a Tertiary Cancer Center from India
}

\author{
Sanjay M. Hunugundmath ${ }^{1}$ Sumit Basu ${ }^{1}$ Bhooshan Zade ${ }^{1}$ Vikram Maiya ${ }^{1}$ Rahul Sharma ${ }^{1}$ \\ Ashok Bhanage $^{1}$ Sathiyanarayanan Vatyam ${ }^{1}$ \\ ${ }^{1}$ Ruby Hall Clinic, Pune, Maharashtra, India \\ Address for correspondence Sanjay M. Hunugundmath, DNB \\ MNAMS, Ruby Hall Clinic, 40, Sassoon Road, Pune 411001, \\ Indian J Neurosurg 2023;12:15-21. \\ Maharashtra, India (e-mail: drsanjaymh@gmail.com).
}

\begin{abstract}
Objectives This article assesses the treatment outcomes in the patients diagnosed with arteriovenous malformations (AVMs) treated with stereotactic radiosurgery. Materials and Methods We retrospectively analyzed 30 patients diagnosed with AVM treated between 2010 and 2018. The median age at presentation was 30 years (range: 14-60 years). The median planning target volume (PTV) was $6.8 \mathrm{~mL}$ (range: $0.9-54$ $\mathrm{mL}$ ). The median dose prescribed was $18 \mathrm{~Gy}$ (range: 16-24 Gy). Modified radiosurgerybased AVM grading score was calculated for all the patients.

Results The median follow-up of the entire cohort was 60 months (range: 24-96 months). The obliteration rates for patients followed up for 3 and 5 years were 75 and $86.1 \%$, respectively. Age ( $<35$ years; $p=0.007)$ and PTV ( $<7 \mathrm{~mL} ; p=0.04)$, had better

Keywords

- AVM

- SRS

- obliteration rates obliteration rates. Three patients had hemorrhage, from the AVM after irradiation. None of them were fatal.

Conclusion Stereotactic radiosurgery is a preferred noninvasive treatment modality with acceptable morbidity.
\end{abstract}

\section{Introduction}

Intracranial arteriovenous malformations (AVMs) are developmental anomalies that present with parenchymal or intraventricular bleeding, resulting in morbidity exceeding 10 to $20 \%{ }^{1}$ The annual rate of hemorrhage from intracranial AVMs has been reported to be between 2 and $4 \%$. The primary goal of management in these patients is to prevent rebleed. ${ }^{2}$ Endovascular embolization has been used to treat AVMs, but its role as a sole treatment modality in achieving complete obliteration is limited. ${ }^{3}$ Microsurgery remains the treatment of choice for patients with small superficial AVMs that have bled. Stereotactic radiosurgery (SRS) has emerged as a definite role in the management of these AVMs, which are small as well as deep-seated AVMs that are associated with a higher surgical morbidity. ${ }^{4}$

\section{Objectives}

This article assesses treatment outcomes in patients diagnosed with AVMs treated by linear accelerator (LINAC)-based single-fraction SRS.

\section{Materials and Methods}

We retrospectively analyzed 35 patients diagnosed with intracranial AVM treated with LINAC-based radiosurgery article published online April 19, 2021
DOI https://doi.org/ $10.1055 / \mathrm{s}-0041-1724464$. ISSN 2277-954X.

\footnotetext{
(c) 2021. Neurological Surgeons' Society of India. All rights reserved. This is an open access article published by Thieme under the terms of the Creative Commons Attribution-NonDerivative-NonCommercial-License, permitting copying and reproduction so long as the original work is given appropriate credit. Contents may not be used for commercial purposes, or adapted, remixed, transformed or built upon. (https://creativecommons.org/ licenses/by-nc-nd/4.0/)

Thieme Medical and Scientific Publishers Pvt. Ltd., A-12, 2nd Floor, Sector 2, Noida-201301 UP, India
} 
between 2010 and 2018. Initial assessment was done for selection of cases based on size of the nidus up to $4 \mathrm{~cm}$, location in the eloquent/critical area of the brain which would cause high chances of neurological deficit with surgical intervention and patients who refused for any surgical intervention and opted for radiosurgery. Patients were taken up for singe-fraction SRS after an informed consent. They underwent magnetic resonance imaging (MRI) scan and digital subtraction angiography (DSA) at least 1 day prior to SRS as a part of the planning procedure. MRI scan was performed, and axial postcontrast MRI sections were obtained with $1 \mathrm{~mm}$ slice thickness with no interslice gap at the equal size matrix $(256 \times 256)$ and transferred to iPlan work station for fusion with computed tomography (CT) planning images. Patients were admitted 1 day prior to SRS, and on the day of SRS stereotactic frame was fixed under local anesthesia over the rigid skull bone. Over the last 4 years we have moved from frame-based SRS to frameless SRS. This technique of frameless SRS was developed in our institute, and the methodology was presented in the 2015 ISRS conference held at Yokohoma, Japan ${ }^{5}$. We then fuse the MRI and the pretreatment DSA for all patients on the day of SRS, and delineate the target for the nidus in the presence of neurosurgeons and radiologists. Patients underwent SRS using Siemens ONCOR impression plus LINAC with micromultileaf collimators (mMLCs) using multiple noncoplanar fields which has 40 pairs of mMLC leaves. The projected leaf width at the isocenter is $2.5 \mathrm{~mm}$ giving a maximum field size of $12 \times 10 \mathrm{~cm}$. The planning was done using Brainlabs iPlan software. The nidus and organs at risk such as eye, lens, optic nerve, optic chiasm, brain stem, and normal brain were contoured after verifying the fusion. We used a modified radiosurgery-based AVM grading scoring ${ }^{6}$ for all patients prior to the procedure. The equation used to calculate AVM score was:

AVM score $=(0.1)($ volume, $\mathrm{mL})+0.02($ age, years $)+0.5$ (location)

The median modified AVM score was 1.47 (range: $0.50-$ 5.68). - Figure 1 shows an AVM contoured and planned on Brainlabs iPlan software. The follow-up was done by clinical examination as well as serial MRI angiography or DSA for all patients.

\section{Results}

The median follow-up of the entire cohort was 84 months (range: 24-96 months). Male-to-female ratio was 26:9. Out of 35 patients, 20 patients had only SRS, and 15 patients had onyx embolization followed by SRS. There were nine (26\%) patients with hemorrhages, while five patients (14\%) presented with neurological deficits. The median age at presentation was 30 years (range: 14-60 years). The median planning target volume (PTV) was $6.8 \mathrm{~mL}$ (range: 0.9-54.0 mL). The median dose prescribed was $18 \mathrm{~Gy}$ (range: 16-24 Gy).

The actuarial complete obliteration rates was $71 \%$. Out of 35 patients, 25 had complete obliteration on MRI and DSA and only 10 had partial obliteration. The obliteration rates, based on a modified radiosurgery-based AVM grading scale for a score of $\leq 1,>1$ to $\leq 2$, and $>2$, were $84.7,60$, and $54 \%$, respectively. On logistic regression, there was no statistical correlation between obliteration rates and AVM score, but there was a trend favoring better obliteration rates for AVM score of $\leq 1$. There was no statistically significant difference seen in patients who had prior embolization followed by SRS and upfront SRS $(p=0.44)$. The Kaplan-Meier curves for the obliteration are shown in - Fig. 2

On univariate analysis, age $(<35$ years; $p=0.007)$ and PTV $(<10 \mathrm{~mL} ; p=0.04)$, had better obliteration rates. Two $(5.7 \%)$ patients had hemorrhage from the AVM after irradiation. Both patients had partial obliteration after initial SRS. They opted for treatment in the form of embolization post-SRS for the rebleed. There has been no mortality in our group of patients to date. Three patients had neurological deficits postirradiation, in terms of transient motor deterioration which resolved with short course of steroids. All patients were followed up with either 6 monthly MRI or DSA, every visit to document the status of the lesion. Patients who had complete obliteration on MRI were subjected to DSA for the confirmation. No other patient had any permanent complication related to SRS. - Fig. 3 shows the follow-up MRI angiogram of a patient, 18 months posttreatment with near-total obliteration of the AVM. - Fig. 4 shows the DSA of the same patient, where there is no residual AVM nidus. The demographic profile of the patients is summarized
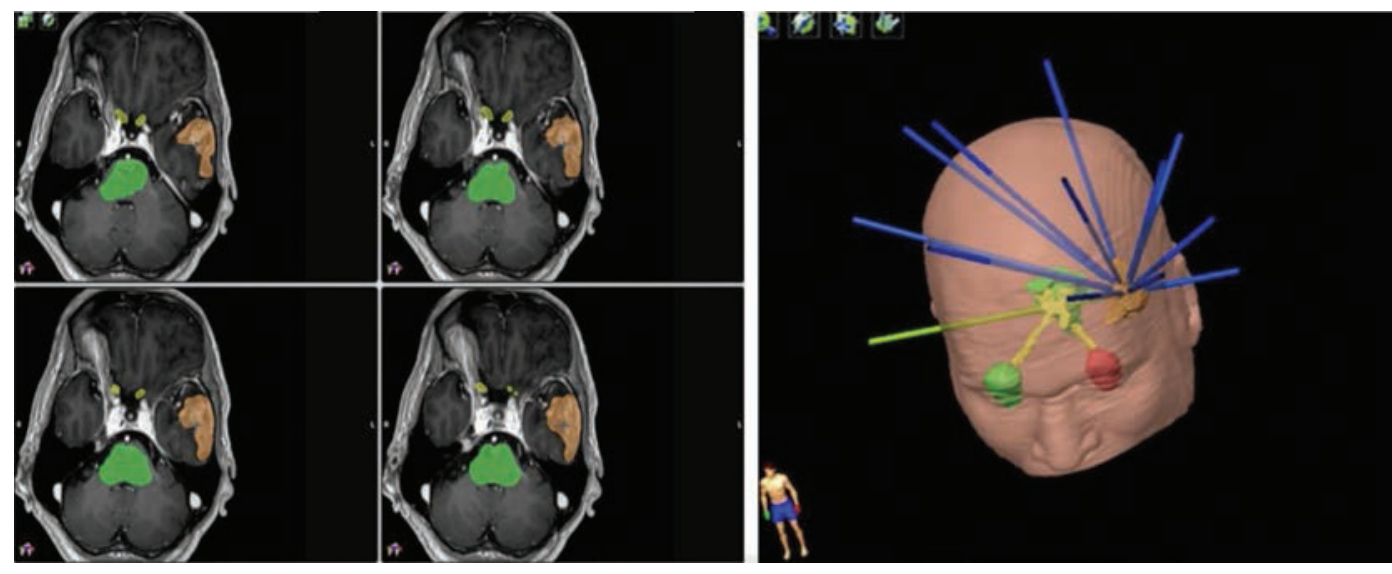

Fig. 1 Arteriovenous malformation in the left temporal region, contoured and planned on Brainlabs iPlan software. 


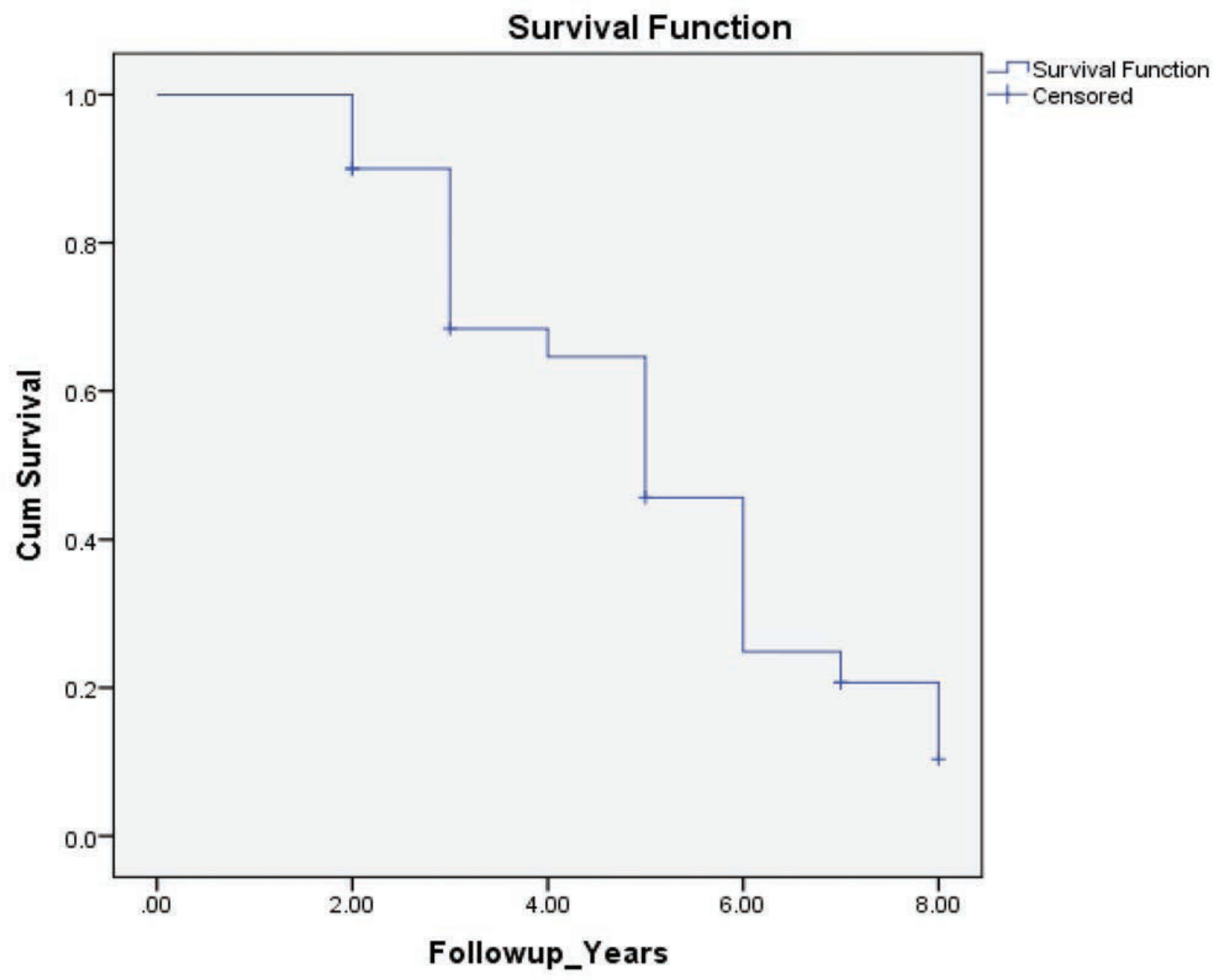

Fig. 2 Kaplan-Meier curve for obliteration rates.

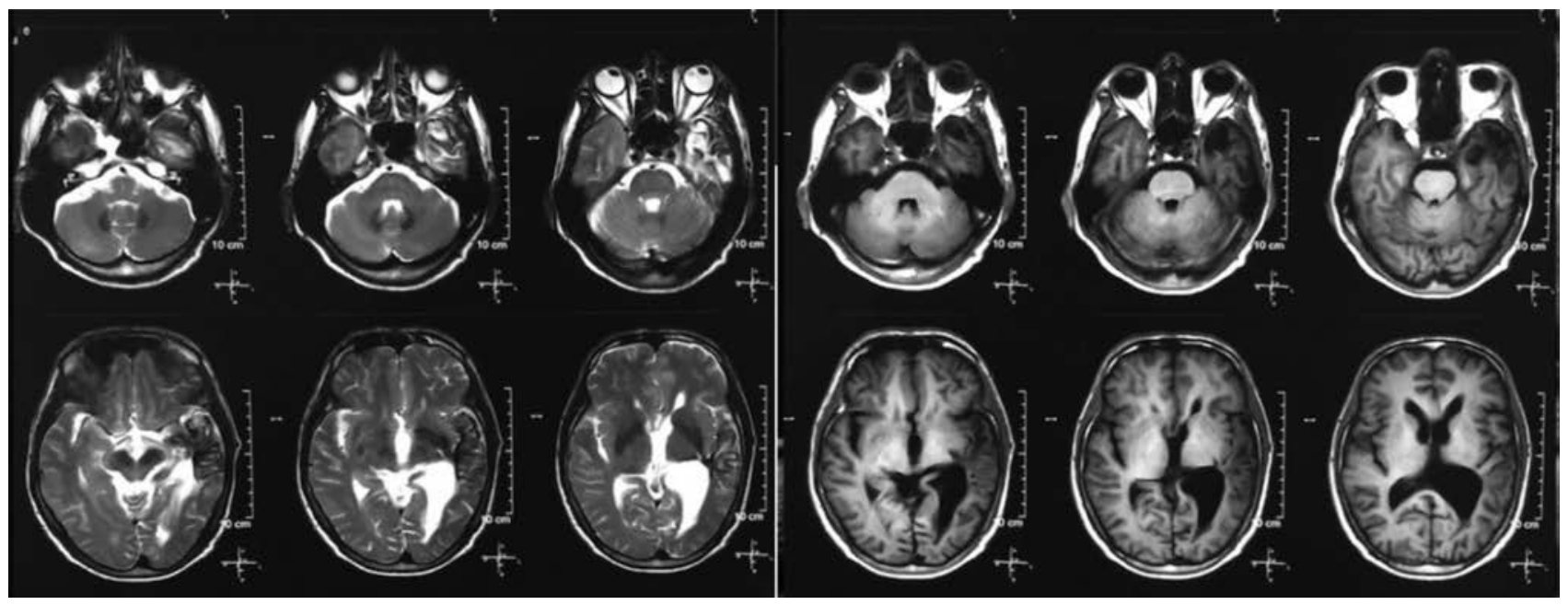

Fig. 3 Follow-up scans 18 months posttreatment, showing no residual arteriovenous malformation (AVM), with the complete obliteration on magnetic resonance imaging (MRI) angiogram and digital subtraction angiography (DSA). 


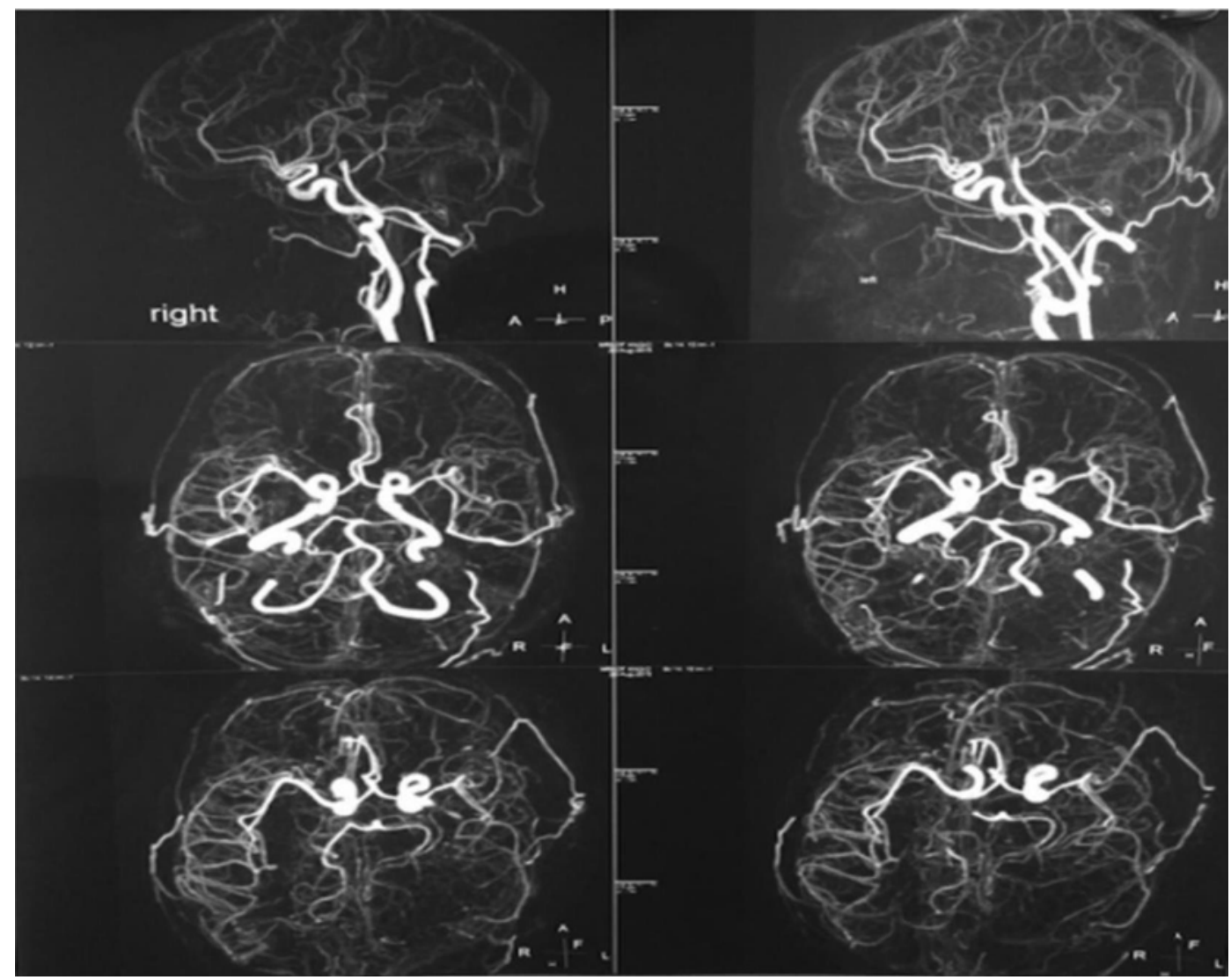

Fig. 4 Digital subtraction angiography posttreatment showing complete obliteration of arteriovenous malformation.

in -Table 1. The dosimetric profile and the treatment characteristics are summarized in - Table 2.

\section{Discussion}

Cerebral AVMs are abnormal connections between arteries and veins, with poor vessels, that shunt blood directly from arterial circulation to venous system without involving capillaries. The high pressure flow within them and abnormal shunting makes them vulnerable to ruptures and hemorrhages. $^{7}$ They commonly present with brain hemorrhage, headaches, and neurological deficits. The gold standard for diagnosing AVM in the current era is CT and magnetic resonance angiography. ${ }^{8}$

The radiobiological effect of SRS on AVM is a quite complex theory. It is explained that the immediate effect of SRS is damage to the endothelial cells of the vessels in the nidus, mediated by release of tissue-specific cytokines. This is followed by initiation of a chronic inflammatory process, with formation of granulation tissue that has fibroblasts and new capillaries. Myofibroblasts, which are actin-producing fibroblasts, have been detected in the region of radiation, and these have been postulated to exert contractile properties and facilitate AVM obliteration. This whole

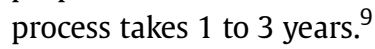

Moving on to the management of AVMs, various treatment modalities like surgery, embolization, surgery followed by embolization, or embolization followed by SRS are used in many cases. The selection of which modality is preferred is purely based on the characteristics of the lesion, the location, and the size of the lesion. And sometimes each of these modalities are combined or used separately. ${ }^{10}$ But within the last decades or so, radiosurgery alone has become increasingly popular as a noninvasive treatment of small AVMs, as well as deep-seated AVMs that are associated with a higher surgical morbidity and it can deliver very high dose in a small volume with minimal irradiation of normal tissue around the area.

In our institute every case was discussed at multidisciplinary meeting in the presence of neuroradiologists, neurosurgeons, and interventional radiologists. Our selection criteria was based on the size of the nidus up to $4 \mathrm{~cm}$, location in the eloquent/critical area of the brain which would cause high chances of neurological deficit with surgical intervention, failure to obliterate after embolization, and patients who refused for any surgical intervention. AVM score was calculated for all the patients, and if scored more than 3 , then SRS was not offered to such patients.

There are various factors identified which affect the obliteration rates such as smaller AVM volume, higher marginal dose of radiation, lower modified PollockFlickinger score, young age, and absence of history of prior embolization. All these factors have been documented to have correlation with higher obliteration rates in a series reporting on AVMs. ${ }^{11,12}$

In our cohort of patients, age ( $<35$ years) and PTV $(<10 \mathrm{~mL})$, were found to be significant factors for obliteration rates. In 
Table 1 The demographic profile of the patients

\begin{tabular}{|l|l|}
\hline Variables & $N$ \\
\hline Age at presentation (median) & 30 y (range: 14-60) \\
\hline Gender & \\
\hline Male & 26 \\
\hline Female & 09 \\
\hline Hemorrhage at presentation & \\
\hline Yes & 11 \\
\hline No & 24 \\
\hline Primary presenting symptom & \\
\hline Headache & 21 \\
\hline Seizures & 09 \\
\hline Others & 05 \\
\hline Embolization & \\
\hline Yes & 15 \\
\hline No & 20 \\
\hline Site of AVM & \\
\hline Frontoparietal & 11 \\
\hline Temporal & 06 \\
\hline Parietal & 05 \\
\hline Thalamic & 02 \\
\hline Corpus callosum & 03 \\
\hline Occipital & 05 \\
\hline Cerebellum & 03 \\
\hline Modified AVM score & \\
\hline$<1$ & 18 \\
\hline $1-\leq 2$ & 09 \\
\hline$>2$ & 08 \\
\hline & \\
\hline & \\
\hline
\end{tabular}

Abbreviation: AVM, arteriovenous malformation.

many series smaller AVMs have been reported to have higher obliteration rates as it allows prescription of higher dose of radiation. Dose of more than $18 \mathrm{~Gy}$ have reported to have obliteration of 50 to $60 \%{ }^{13,14}$ We also found that the modified radiosurgery-based AVM score of $<1$ had better obliteration rates than the higher scores, but it was not statistically significant due to smaller sample size of our cohort. Embolization of AVMs is considered often not a curative option, but it does decrease the chances of rebleed while waiting for SRS. ${ }^{3}$ History of previous embolization could result in a suboptimal definition of the AVM target for SRS, this could result in AVM not been completely obliterated. ${ }^{15}$ In our series there was no correlation between previous history of embolization and obliteration rates. The significant predictor factors are summarized in - Table 3.

Obliteration of AVMs after SRS has been reported to range from 60 to $92 \%$, with the obliteration rate exceeding $70 \%$ in most series, comparable to the obliteration rates of our cohort of patients as shown in - Table 4 .
Table 2 The dosimetric profile and treatment characteristics

\begin{tabular}{|l|l|}
\hline Variable & Value \\
\hline Nidus volume (mL) & 6.8 (median) (Range: $0.9-54)$ \\
\hline Dose (Gy) & 18 (median) (Range: 16-24) \\
\hline $\begin{array}{l}\text { 12 Gy normal brain } \\
\text { volume (mL) }\end{array}$ & 12.5 (median) (Range: 0.6-84) \\
\hline Isodose coverage (\%) & 90 (median) (Range: $85-95)$ \\
\hline Optic chiasm dose (Gy) & 0.5 (median)(Range: $0.19-6.64)$ \\
\hline Brain stem dose (Gy) & 1.97 (median)(Range: $0.3-8.25)$ \\
\hline Number of beams & 12 (median)(Range: $11-14)$ \\
\hline Follow-up duration (mo) & 60 (median) (Range: $24-96)$ \\
\hline $\begin{array}{l}\text { Follow-up status on } \\
\text { imaging }\end{array}$ & 25 patients (71\%) \\
\hline $\begin{array}{l}\text { MRI proven complete } \\
\text { obliteration }\end{array}$ & 25 patients (71\%) \\
\hline $\begin{array}{l}\text { DSA proven complete } \\
\text { obliteration }\end{array}$ & 10 patients (29\%) \\
\hline $\begin{array}{l}\text { MRI proven partial } \\
\text { obliteration }\end{array}$ & \\
\hline
\end{tabular}

Abbreviations: DSA, digital subtraction angiography; MRI, magnetic resonance imaging.

Table 3 Predictors for obliteration rates

\begin{tabular}{|l|l|l|}
\hline Subject no. & Predictors for obliteration rates & $p$-Value \\
\hline 1 & Age $(<35,>35 \mathrm{y})$ & 0.007 \\
\hline 2 & PTV $(<10,>10 \mathrm{~mL})$ & 0.04 \\
\hline
\end{tabular}

Abbreviation: PTV, planning target volume.

Complication after SRS has been reported in many series post-SRS almost up to $15 \%$ in the different series of LINACbased SRS in AVMs, ${ }^{4}$ with permanent neurological deficits of up to $5 \%$. Larger AVM volume, higher Spetzler-Martin grade, and higher Pollock-Flickinger score have been reported to have a higher risk of developing post-SRS neurological deficits. ${ }^{21}$ In our cohort of patients only three patients developed complication, in terms of transient motor deterioration which was reversible with a short course of steroids and physiotherapy. None of our patients have experienced permanent neurological deficits. Pre-SRS, 5 (17\%) of our patients had neurological deficits, all these 5 patients had presented with hemorrhage and post-SRS on follow-up imaging had complete obliteration. They also recovered with their neurological deficits, and the recovery of the deficit could be well due to resolution of the bleeding, since all 5 of them had complete obliteration. Almost $60 \%$ of patients presented with hemorrhage from AVM before SRS in most series, ${ }^{22}$ so the main goal of SRS is to prevent rebleeding of the AVM.

The risk of rebleeding remains up to the time AVM is obliterated. There is no strong evidence yet to claim that partial obliteration would minimize the risk of a bleed. Most of the series have reported a rebleed rate of between 1 and $6.8 \%{ }^{23}$ In our series, 2 (5.7\%) patients had rebleed post-SRS, and none of them were fatal. We believe that it could be due 
Table 4 Obliteration rates from the published literature

\begin{tabular}{|c|c|c|c|c|c|}
\hline Author & $\begin{array}{l}\text { Patient number } \\
\text { (n) }\end{array}$ & $\begin{array}{l}\text { Median dose } \\
\text { (Gy) }\end{array}$ & $\begin{array}{l}\text { Median } \\
\text { follow-up } \\
\text { (mo) }\end{array}$ & $\begin{array}{l}\text { Obliteration rate } \\
\text { (\%) }\end{array}$ & $\begin{array}{l}\text { Rate of neurological } \\
\text { complications } \\
\text { (\%) }\end{array}$ \\
\hline Tamura et $\mathrm{al}^{16}$ & 220 & 22 & 32 & 69 & 3.6 \\
\hline Quigg et al ${ }^{17}$ & 662 & 20 & 132 & 70 & 3.8 \\
\hline Skjøth-Rasmussen-et al ${ }^{18}$ & 1,012 & 20 & 96 & 69 & 2.1 \\
\hline Ding et al $^{19}$ & 217 & 22 & 64 & 90 & 3.6 \\
\hline Bowden et $\mathrm{al}^{20}$ & 116 & 18 & 101 & 82 & 1 \\
\hline Our series & 35 & 18 & 84 & 71 & 5.7 \\
\hline
\end{tabular}

to low marginal dose of $16 \mathrm{~Gy}$ in all these 2 patients, and presence of multiple draining veins.

Outcome of radiosurgery for AVM is usually assessed with serial MRI after 6 months of completion of SRS and DSA at 1-year interval. We routinely did MRI on follow-up every 6 months for all our patients. If MRI showed obliteration of the AVM, then the patient was subjected to DSA for the confirmation.

The late effect of radiation is responsible for the obliteration of the nidus. There is latency period of up to 2 years between SRS procedure and obliteration of the nidus. During this latency period, before complete obliteration, the rate of hemorrhage is similar to natural history $(3-4 \%$ | year). ${ }^{24}$ As a result, SRS lacks protective effect before complete obliteration of the AVM. Since obliteration takes time, SRS is not always successful and carries a risk of hemorrhage during the period of latency. Complete obliteration rate is entirely dependent upon proper selection of cases, ${ }^{25}$ and they need a long-term follow-up to determine the cognitive sequelae, delayed complications, and rarely AVM recurrence. Since there are no prospective analyses on management of AVMs based on available modalities of treatment, our report may be one among the few from India, highlighting the outcome with SRS.

We are aware of the fact that our data are based on small number of patients. But we still could show an excellent response in terms of obliteration rate, and all our patients showed good tolerance and favorable toxicity profile.

\section{Conclusion}

SRS is a preferred noninvasive treatment modality for complete obliteration of smaller volume AVMs that are associated with high surgical morbidity. Selection of appropriate case plays a vital role in achieving acceptable obliteration rates with minimal toxicity.

Conflict of Interest

None declared.

\section{References}

1 Majumdar M, Tan LA, Chen M. Critical assessment of the morbidity associated with ruptured cerebral arteriovenous malformations. J Neurointerv Surg 2016;8(02):163-167
2 Gross BA, Storey A, Orbach DB, Scott RM, Smith ER. Microsurgical treatment of arteriovenous malformations in pediatric patients: the Boston Children's Hospital experience. J Neurosurg Pediatr 2015;15(01):71-77

3 Soltanolkotabi M, Schoeneman SE, Alden TD, et al. Onyx embolization of intracranial arteriovenous malformations in pediatric patients. J Neurosurg Pediatr 2013;11(04):431-437

4 Zacest AC, Caon J, Roos DE, Potter AE, Sullivan T. LINAC radiosurgery for cerebral arteriovenous malformations: a single centre prospective analysis and review of the literature. J Clin Neurosci 2014;21(02):241-245

5 Sathiya VKNarayanan, Nirhali AA, Luharia A, Mondekar PFrameless stereotactic treatments using carbon target imaging, column rotation and unflat beams. Paper presented at: Proceedings presented at 12th ISRS, International Stereotactic Radiosurgery Congress; June 7-11, 2015, Yokohama, Japan

6 Wegner RE, Oysul K, Pollock BE, et al. A modified radiosurgerybased arteriovenous malformation grading scale and its correlation with outcomes. Int J Radiat Oncol Biol Phys 2011;79 (04):1147-1150

7 Wang HC, Chang RJ, Xiao F. Hypofractionated stereotactic radiotherapy for large arteriovenous malformations. Surg Neurol Int 2012;3(Suppl 2):S105-S110

8 Ferrara AR. Brain arteriovenous malformations. Radiol Technol2011;82;06

9 Szeifert GT, Kemeny AA, Timperley WR, Forster DM. The potential role of myofibroblasts in the obliteration of arteriovenous malformations after radiosurgery. Neurosurgery 1997;40(01): 61-65, discussion 65-66

10 Barr JC, Ogilvy CS. Selection of treatment modalities or observation of arteriovenous malformations. Neurosurg Clin N Am 2012;23(01):63-75

11 Matsuo T, Kamada K, Izumo T, Hayashi N, Nagata I. Linear accelerator-based radiosurgery alone for arteriovenous malformation: more than 12 years of observation. Int J Radiat Oncol Biol Phys 2014;89(03):576-583

12 Lecavalier-Barsoum M, Roy D, Doucet R, et al. Long-term results of radiosurgery for cerebral arteriovenous malformations. Can J Neurol Sci 2013;40(02):182-186

13 Fokas E, Henzel M, Wittig A, Grund S, Engenhart-Cabillic R. Stereotactic radiosurgery of cerebral arteriovenous malformations: long-term follow-up in 164 patients of a single institution. J Neurol 2013;260(08):2156-2162

14 Potts MB, Sheth SA, Louie J, et al. Stereotactic radiosurgery at a low marginal dose for the treatment of pediatric arteriovenous malformations: obliteration, complications, and functional outcomes. J Neurosurg Pediatr 2014;14(01):1-11

15 Xu F, Zhong J, Ray A, Manjila S, Bambakidis NC. Stereotactic radiosurgery with and without embolization for intracranial arteriovenous malformations: a systematic review and metaanalysis. Neurosurg Focus 2014;37(03):E16 
16 Tamura N, Hayashi M, Chernov M, et al. Outcome after Gamma Knife surgery for intracranial arteriovenous malformations in children. J Neurosurg 2012;117(Suppl 1):150-157

17 Quigg M, Yen CP, Chatman M, et al. Risks of history of diabetes mellitus, hypertension, and other factors related to radiation-induced changes following Gamma Knife surgery for cerebral arteriovenous malformations. J Neurosurg 2012;117(Suppl 1):144-149

18 Skjøth-Rasmussen J, Roed H, Ohlhues L, Jespersen B, Juhler M. Complications following linear accelerator based stereotactic radiation for cerebral arteriovenous malformations. Int J Radiat Oncol Biol Phys 2010;77(02):542-547

19 Ding D, Yen CP, Xu Z, Starke RM, Sheehan JP. Radiosurgery for lowgrade intracranial arteriovenous malformations. J Neurosurg 2014;121(02):457-467

20 Bowden G, Kano H, Caparosa E, et al. Stereotactic radiosurgery for arteriovenous malformations of the postgeniculate visual pathway. J Neurosurg 2015;122(02):433-440
21 Pan DH, Kuo YH, Guo WY, et al. Gamma Knife surgery for cerebral arteriovenous malformations in children: a 13-year experience. J Neurosurg Pediatr 2008;1(04):296-304

22 Kano H, Kondziolka D, Flickinger JC, et al. Stereotactic radiosurgery for arteriovenous malformations, part 2: management of pediatric patients. J Neurosurg Pediatr 2012;9 (01):1-10

23 Ding D, Yen CP, Starke RM, Xu Z, Sheehan JP. Radiosurgery for ruptured intracranial arteriovenous malformations. J Neurosurg 2014;121(02):470-481

24 Andrews DW, Bednarz G, Evans JJ, Downes B. A review of 3 current radiosurgery systems. Surg Neurol 2006;66(06):559-564

25 Flickinger JC, Kondziolka D, Maitz AH, Lunsford LD. Analysis of neurological sequelae from radiosurgery of arteriovenous malformations: how location affects outcome. Int J Radiat Oncol Biol Phys 1998;40(02):273-278 